\title{
The effect of ALDH2 rs671 gene mutation on clustering of cardiovascular risk factors in a big data study of Chinese population: associations differ between the sexes
}

Danchen Wang ${ }^{1 \dagger}$, Yutong Zou ${ }^{1 \dagger}$, Songlin Yu ${ }^{1 \dagger}$, Songbai Lin ${ }^{2}$, Honglei Li ${ }^{1}$, Yicong Yin ${ }^{1}$, Ling Qiu ${ }^{1 *} \mathbb{D}$, Tengda Xu ${ }^{2^{*}}$ and Jie $\mathrm{Wu}^{1 *}$

\begin{abstract}
Background: The ALDH2 rs671 genetic polymorphism has been linked with cardiovascular diseases (CVDs), but comprehensive epidemiological studies are lacking. An observational, retrospective big data study was carried out to evaluate the associations between this polymorphism and clustering cardiovascular risk factors (CRFs) in a Chinese population.

Methods: A total of 13,101 individuals (8431 males and 4670 females) were enrolled. Genetic polymorphism was assessed using gene mutation detection kits, coupled with an automatic fluorescent analyzer. Other data were obtained from the records of the Department of Health Care at Peking Union Medical College Hospital.
\end{abstract}

Results: Comparing the concentrations of common biochemical analytes, including BMI, SBP, DBP, ALT, AST, Y-GT, TBil, $\mathrm{Cr}$, Glu, TC, TG, and HDL-C among individuals with the GG, GA, and AA genotypes of ALDH2 rs671, we found significant differences in males (all $p<0.001$ ), but not in females. For males, the frequencies of hypertension, diabetes, and obesity were significantly higher for GG than for GA or AA (all $p<0.05$ ). However, there was no significant difference for dyslipidemia, and no significant associations were observed for all frequencies in females. The prevalence of individuals with 1-4 CRFs was significantly higher among GG males than those carrying GA or AA, and fewer GG males had non-CRFs (all $p<0.05$ ).

Conclusion: Polymorphisms of ALDH2 rs671 are associated with clustering CRFs, especially hypertension and diabetes in males, but not in females. These associations are likely mediated by alcohol intake, which is also associated with this gene.

Keywords: ALDH2, rs671, Cardiovascular disease, Cardiovascular risk factor

*Correspondence: lingqiubj@163.com; Xutd@pumch.cn; wuj8289@163.com †Danchen Wang, Yutong Zou and Songlin Yu contributed equally to this work

1 Department of Laboratory Medicine, Peking Union Medical College Hospital, Chinese Academy of Medical Sciences, No. 1 Shuaifu Yuan, Dongcheng District, Beijing 100730, China

${ }^{2}$ Department of Health Care, Peking Union Medical College Hospital, Chinese Academy of Medical Sciences, No. 1 Shuaifu Yuan, Dongcheng District, Beijing 100730, China

\section{Background}

Cardiovascular diseases (CVDs) is one of the leading causes of mortality worldwide $[1,2]$, with more than 55 million deaths caused by CVDs in 2017 [3]. Hypertension, diabetes, obesity, and dyslipidemia are well known as cardiovascular disease risk factors (CRFs) [4-7]. CRFs are common, carry an increased risk of CVDs, and their prevalence increases with age [1]. Moreover, the effect of 
clustering CRFs is greater than the effect of single CRFs on the same individual [2].

Alcohol is one of the most widely used recreational substances worldwide, and its intake is a leading risk factor for global disease burden, including CVDs [4-7]. Despite general recognition that alcohol intake has a negative effect on health, it has been estimated that the average ethanol consumption of a person aged more than 15 years is approximately $19.7 \mathrm{~mL}$ per day [8]. Other data suggest that global adult per-capita consumption is estimated to increase from 6.5 (95\% CI: 6.01-6.9L) in 2017 to $7.6 \mathrm{~L}$ (95\% CI: $6.5-10.2 \mathrm{~L}$ ) by 2030 [9].

As an essential bioactivating enzyme, ALDH2 can degrade acetaldehyde to nontoxic acetic acid. It is encoded by the $A L D H 2$ gene, which is commonly polymorphic in East Asian populations [5]. It has been reported that as many as $30-50 \%$ of East Asians carry an inactive form of ALDH2-rs671 resulting from a single G-to-A transition causing replacement of glutamate to lysine at position 504, and drastically reducing the carrier's capacity to metabolize alcohol [10-12]. The frequency of the A allele was reported to be 0.21 in China [13].

ALDH2 activation has also been found to be associated with improved mitochondrial function and the remodeling of ventricular function [14, 15], and many studies have reported an association between ALDH2 and CVDs $[1,2,5,13,15,16]$. The most important known feature of the myocardial cardio-protective role of ALDH2 is the clearance of toxic aldehydes such as 4-hydroxynonenal and its adducts, which can be induced by acute oxidative stress upon cardiac ischemia or reperfusion [17-19]. Activation of ALDH2 may slow down the progression of atherosclerosis via attenuation of endoplasmic reticulum stress and apoptosis in smooth muscle cells [16].

Genetic association studies have recently shown that the $A L D H 2$ rs671 polymorphism is a significant risk factor for hypertension, diabetes, and coronary heart diseases in Asian people [20,21]. Although a number of studies have focused on the association between $A L D H 2$ and single CRFs such as hypertension, diabetes, obesity, and dyslipidemia, and analyses [20, 21], the association has not been clearly defined. Thus, detailed studies focused on the association between $A L D H 2$ and clustering CRFs are needed. Interestingly, there is an increasing interest in obtaining annual routine physical examination in China, which has resulted in more data on the health status of the population. Using data from hospital and laboratory information systems is not only cost-effective but also efficient.

Therefore, this retrospective study, which is based on clinical big data, aimed to (1) evaluate the distribution of $A L D H 2$ rs671 genotypes, (2) evaluate the prevalence of single and clustering CRFs in China, and (3) explore the association between $A L D H 2$ rs671 genotypes and CRFs.

\section{Methods \\ Data collection}

The study included 13,101 patients aged $\geq 19$ years old. Data including demographic information, common biochemical analytes, and medical history from November, 2013 to October, 2018, were obtained from the hospital information system (HIS) and laboratory information system (LIS) of the Department of Health Care at Peking Union Medical College Hospital (PUMCH). With a unique identification code identifying duplicated measurements, only the first record of each person was saved.

\section{Laboratory measurement}

Genomic DNA was extracted from whole peripheral blood via DNA extraction kits (Tianlong Technology Co. LTD, Xi'an, China) and rs671 polymorphism status was determined by an $A L D H 2$ gene mutation detection kit, coupled with an automatic fluorescent analyzer (Beijing market gene technology Co. LTD, Beijing, China). Height, weight, and blood pressure were measured by well-trained nurses and doctors, and body mass index (BMI) was calculated as weight divided by height squared. Common biochemical analytes including Albumin (Alb), alanine aminotransferase (ALT), Aspartate aminotransferase (AST), glutamyl transpeptidase $(\gamma-\mathrm{GT})$, total bilirubin (TBil), creatinine $(\mathrm{Cr})$, glucose $(\mathrm{Glu})$, total cholesterol (TC), triglyceride (TG), high density lipoprotein cholesterol (HDL-C), and low density lipoprotein cholesterol (LDL-C) were measured by a Roche C8000 automatic analyzer (Roche C8000, Basel, Switzerland) with corresponding reagents, calibrators, and quality control materials. All records including quality control and external quality assessment during this period were reviewed and deemed sound.

\section{Definition of cardiovascular disease risk factors (CRFs)}

In this study, we evaluate the association between the $A L D H 2$ rs671 polymorphism and major CRFs including hypertension, diabetes, obesity, and dyslipidemia. We used the following specific definitions, as previously described [22]:

(1) Hypertension: systolic blood pressure (SBP) $\geq 140 \mathrm{mmHg}$ and/or diastolic blood pressure (DBP) $\geq 90 \mathrm{mmHg}$ [23].

(2) Diabetes: fasting blood Glu $\geq 7 \mathrm{mmol} / \mathrm{L}$ or $\mathrm{HbA1C}$ $\geq 6.5 \%$.

(3) Obesity: BMI $\geq 28 \mathrm{~kg} / \mathrm{m}^{2}$. 
(4) Dyslipidemia: at least one of the following: TC $\geq 5.2 \mathrm{mmol} / \mathrm{L}, \quad$ TG $\geq 1.7 \mathrm{mmol} / \mathrm{L}$, $\mathrm{HDL}-\mathrm{C}<1.0 \mathrm{mmol} / \mathrm{L}$, and $/$ or LDL-C $\geq 3.4 \mathrm{mmol} / \mathrm{L}$.

\section{Statistical analysis}

Excel 2010 (Microsoft Inc., USA), SPSS 20.0 software (SPSS Inc., Chicago, IL, USA), and Graphpad prism for Windows (GraphPad Software, San Diego, CA), were used for our statistical analyses. The Mann-Whitney $U$ or Kruskal-Wallis tests were used to compare measurements among groups, and the comparisons of prevalence were conducted by Chi-square test. Multivariate logistic regression analysis was used to correct for covariates and calculate the odds ratios (ORs), with 95\% confidence intervals (CIs), of genotype associations with CRFs. The results were considered statistically significant when the two-sided $p$-value was $<0.05$.

\section{Results}

\section{Basic characteristics of the studied population}

The baseline demographic and clinical characteristics of studied individuals divided by $A L D H 2$ polymorphism and sex are shown in Table 1. In total, 13,101 individuals including 8431 males and 4670 females were eventually included. The distribution of age was $(49 \pm 9)$ years old, and BMI was $(24.8 \pm 3.8) \mathrm{kg} / \mathrm{m}^{2}$. There was no difference in age by $A L D H 2$ polymorphism in either males or females. However, common clinical measurements including BMI, SBP, DBP, ALT, AST, $\gamma-\mathrm{GT}$, TBil, Cr, Glu,
TC, TG, and HDL-C were significantly different in males (all $p<0.001$ ), though not in females.

\section{ALDH2 rs671 genotype frequency by sex and age}

The distribution of $A L D H 2$ rs671 gene polymorphism among different years (from 2013 to 2018) did not show significant differences $(p=0.946)$. As Fig. 1 and Supplemental Table 1 show, the frequencies of the $A L D H 2$ rs671 genotypes GG, GA, and AA in the total population were $67.9,29.4$, and $2.7 \%$, respectively. These frequencies did not differ significantly by sex. Although there was no significant difference of the overall age distribution of the different genotypes in either males or females, the frequency of AA in individuals aged $\geq 65$ years old was lower than other age groups in both males and females, with the opposite distribution in evidence for GG. Also, the

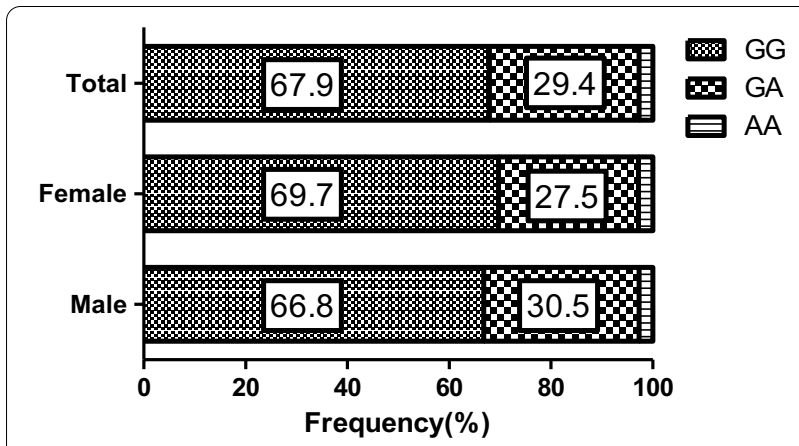

Fig. 1 The frequency of ALDH2 rs671 genotype by sex

Table 1 General characteristics of the enrolled population

\begin{tabular}{|c|c|c|c|c|c|c|c|c|}
\hline & \multicolumn{2}{|l|}{ GG } & \multicolumn{2}{|l|}{ GA } & \multicolumn{2}{|l|}{$\mathrm{AA}$} & \multirow[t]{2}{*}{$P$ in male } & \multirow[t]{2}{*}{$P$ in female } \\
\hline & $\begin{array}{l}\text { Male } \\
(n=5636)\end{array}$ & $\begin{array}{l}\text { Female } \\
(n=3255)\end{array}$ & $\begin{array}{l}\text { Male } \\
(n=2571)\end{array}$ & Female(n=1286) & Male $(n=224)$ & $\begin{array}{l}\text { Female } \\
(n=129)\end{array}$ & & \\
\hline Age (years) & $48 \pm 9$ & $49 \pm 9$ & $49 \pm 9$ & $48 \pm 9$ & $48 \pm 8$ & $48 \pm 9$ & 0.795 & 0.509 \\
\hline $\mathrm{BMI}(\mathrm{kg} / \mathrm{m} 2)$ & $25.8 \pm 3.6$ & $23.4 \pm 3.3$ & $25.4 \pm 3.7$ & $23.1 \pm 3.7$ & $25.2 \pm 4.1$ & $23.3 \pm 3.7$ & $<0.001$ & 0.075 \\
\hline $\mathrm{SBP}(\mathrm{mmHg})$ & $125.2 \pm 15.1$ & $116.3 \pm 16.5$ & $122.5 \pm 14.7$ & $116.1 \pm 18.1$ & $119.5 \pm 13.8$ & $117.2 \pm 20.2$ & $<0.001$ & 0.395 \\
\hline $\mathrm{DBP}(\mathrm{mmHg})$ & $79.2 \pm 10.5$ & $69.2 \pm 10.1$ & $76.8 \pm 9.9$ & $68.5 \pm 10.5$ & $74.7 \pm 10.0$ & $70.4 \pm 11.8$ & $<0.001$ & 0.060 \\
\hline Alb (g/L) & $62.8 \pm 2.9$ & $60.6 \pm 2.9$ & $62.9 \pm 2.9$ & $60.7 \pm 2.9$ & $62.6 \pm 3.3$ & $61.1 \pm 2.9$ & 0.460 & 0.182 \\
\hline $\operatorname{ALT}(\mathrm{U} / \mathrm{L})$ & $25(18,34)$ & $16(12,21)$ & $21(16,31)$ & $15(12,21)$ & $23(18,31)$ & $16(12,22)$ & $<0.001$ & 0.916 \\
\hline AST (U/L) & $20(17,25)$ & $18(15,21)$ & $19(16,23)$ & $18(15,21)$ & $19(17,23)$ & $17(15,21)$ & $<0.001$ & 0.273 \\
\hline Y-GT (U/L) & $36(24,60)$ & $16(12,23)$ & $28(20,43)$ & $16(12,23)$ & $24(18,35)$ & $15(12,25)$ & $<0.001$ & 0.849 \\
\hline Tbil ( $\mu \mathrm{mol} / \mathrm{L})$ & $11.9(9.2,15.3)$ & $9.0(6.9,11.9)$ & $11.2(8.7,14.5)$ & $8.9(7.0,11.5)$ & $10.3(8.0,13.9)$ & $9.3(6.9,11.7)$ & $<0.001$ & 0.743 \\
\hline $\mathrm{Cr}(\mu \mathrm{mol} / \mathrm{L})$ & $79.8 \pm 13.4$ & $60.4 \pm 10.0$ & $81.6 \pm 12.4$ & $61.3 \pm 22.8$ & $83.0 \pm 11.3$ & $59.8 \pm 8.7$ & $<0.001$ & 0.546 \\
\hline Glu (mmol/L) & $5.7 \pm 1.6$ & $5.2 \pm 1.1$ & $5.5 \pm 1.4$ & $5.2 \pm 1.0$ & $5.4 \pm 1.2$ & $5.2 \pm 1.3$ & $<0.001$ & 0.904 \\
\hline $\mathrm{TC}(\mathrm{mmol} / \mathrm{L})$ & $4.82 \pm 0.98$ & $4.89 \pm 0.92$ & $4.69 \pm 0.88$ & $4.88 \pm 0.92$ & $4.67 \pm 0.85$ & $4.88 \pm 1.00$ & $<0.001$ & 0.890 \\
\hline TG (mmol/L) & $1.6(1.2,2.4)$ & $1.1(0.8,1.6)$ & $1.5(1.1,2.2)$ & $1.1(0.8,1.6)$ & $1.4(1.0,2.1)$ & $1.2(0.8,1.6)$ & $<0.001$ & 0.644 \\
\hline $\begin{array}{l}\mathrm{HDL}-\mathrm{C} \\
\quad(\mathrm{mmol} / \mathrm{L})\end{array}$ & $1.11 \pm 0.27$ & $1.39 \pm 0.33$ & $1.08 \pm 0.25$ & $1.38 \pm 0.34$ & $1.05 \pm 0.23$ & $1.35 \pm 0.34$ & $<0.001$ & 0.398 \\
\hline LDL-C (mmol/L) & $3.03 \pm 0.81$ & $3.05 \pm 0.79$ & $3.00 \pm 0.76$ & $3.03 \pm 0.79$ & $3.03 \pm 0.74$ & $2.96 \pm 0.90$ & 0.088 & 0.243 \\
\hline
\end{tabular}


frequency of GA in those aged between 19 and 29years was higher than in other age groups, and the frequency of GG was significantly lower (Supplemental Table 1).

\section{Prevalence of CRFs by rs671 genotype}

The frequencies of CRFs associated with different rs671 genotypes by sex are shown in Table 2 . For males, the frequencies of hypertension, diabetes, and obesity were significantly higher for GG than for GA or AA. However, there was no significant difference in the prevalence of dyslipidemia among the three rs671 genotypes. For females, there was no statistically significant difference in the prevalence of hypertension, diabetes, obesity, or dyslipidemia among the rs671 genotypes (all $p>0.05$ ).

\section{Prevalence of clustering CRFs by rs671 polymorphism}

The non-CRFs were defined as individuals who did not have hypertension, obesity, diabetes, or dyslipidemia. The frequencies of non-CRFs were 15.3, 40.9, and $24.4 \%$ in males, females, and the total population. The respective frequencies of individuals with one, two, three, and four CRFs were $36.9,32.4,12.8$, and $2.5 \%$ in males, $40.0,14.7$, 3.9 , and $0.6 \%$ in females. The major cluster of CRFs comprised hypertension, diabetes, obesity, and dyslipidemia. The frequencies of clustering CRFs by rs671 genotype and sex are shown in Table 3. The sex-stratified frequencies of clustered CRFs among the rs671 genotypes were significantly different in males, but not in females. The frequencies of individuals with two, three, and four CRFs were significantly higher in the population with GG than in those with GA or AA in males, while among males with no CRFs, the frequency of GG was statistically lower than GA or AA. However, there was no significant difference between the frequencies of clustering CRFs and $A L D H 2$ genotype in females.

\section{Multivariate logistic regression analysis}

Multivariate logistic regression analysis results are shown in Table 4. This analysis estimated OR with 95\% CI for each variable, while adjusting for age and other risk factors. Compared with GG, males with GA and AA were less likely to have hypertension (GA: OR $=0.77,95 \%$ CI: 0.69-0.85; AA: $\mathrm{OR}=0.56,95 \% \mathrm{CI}: 0.41-0.75)$. Also, males with GG were more likely to have diabetes than those with GA $(\mathrm{OR}=0.73,95 \% \mathrm{CI}: 0.62-0.87)$. There were no differences in overweight or dyslipidemia among male populations with GG, GA, and AA. For females, there was no significant difference among genotypes in hypertension, diabetes, obesity, or dyslipidemia. In males, though not in females, the proportions of GA and AA decreased with increasing numbers of CRFs.

\section{Discussion}

Based on the distribution of age, the enrolled individuals fairly reflected the distribution of Chinese adults, the frequency of GA, AA and AA during the whole 5 years was $29.4,2.7$ and $17.4 \%$, similar to those of previous studies $[13,24]$. The distribution of $A L D H 2$ rs671 gene polymorphism among different years (from 2013 to 2018) did not show significant differences $(p=0.946)$, which implied the reliability of the measurements without obvious carry-over.

Table 2 Prevalence of CRFs by rs671 genotype and sex

\begin{tabular}{|c|c|c|c|c|c|c|c|c|}
\hline \multirow[t]{2}{*}{ CRFs } & \multicolumn{2}{|l|}{ GG } & \multicolumn{2}{|l|}{$\mathrm{GA}$} & \multicolumn{2}{|l|}{ AA } & \multirow[t]{2}{*}{$P$ in male } & \multirow[t]{2}{*}{$P$ in female } \\
\hline & Male & Female & Male & Female & Male & Female & & \\
\hline Hypertension & 2662 (47.2\%) & $621(19.1 \%)$ & 992 (38.6\%) & 245 (19.1\%) & $66(29.5 \%)$ & $34(26.4 \%)$ & $<0.001$ & 0.118 \\
\hline Obesity & 1320 (23.4\%) & 276 (8.5\%) & 501 (19.5\%) & $113(8.8 \%)$ & $42(18.8 \%)$ & $15(11.6 \%)$ & $<0.001$ & 0.450 \\
\hline Diabetes & $791(14.0 \%)$ & $170(5.2 \%)$ & 279 (10.9\%) & $78(6.1 \%)$ & $26(11.6 \%)$ & $10(7.8 \%)$ & $<0.001$ & 0.284 \\
\hline Dyslipidemia & $4030(71.5 \%)$ & $1614(49.6 \%)$ & 1807 (70.3\%) & 655 (50.9\%) & 152 (67.9\%) & $63(48.8 \%)$ & 0.300 & 0.693 \\
\hline
\end{tabular}

Table 3 Prevalence of clustering CRFs by rs671 genotype and sex

\begin{tabular}{|c|c|c|c|c|c|c|c|c|}
\hline \multirow[t]{2}{*}{ CRFs } & \multicolumn{2}{|l|}{ GG } & \multicolumn{2}{|l|}{ GA } & \multicolumn{2}{|l|}{ AA } & \multirow[t]{2}{*}{$P$ in male } & \multirow[t]{2}{*}{$P$ in female } \\
\hline & Male & Female & Male & Female & Male & Female & & \\
\hline$C R F=0$ & 797 (14.1\%) & 1335 (41.0\%) & 449 (17.5\%) & $521(40.5 \%)$ & 42 (18.8\%) & $52(40.3 \%)$ & $<0.001$ & 0.946 \\
\hline$C R F=1$ & 1993 (35.4\%) & $1311(40.3 \%)$ & 1019 (39.6\%) & 513 (39.9\%) & 101 (45.1\%) & 42 (32.6\%) & $<0.001$ & 0.214 \\
\hline$C R F=2$ & 1895 (33.6\%) & 478 (14.7\%) & 782 (30.4\%) & 185 (14.4\%) & 58 (25.9\%) & 25 (19.4\%) & 0.002 & 0.309 \\
\hline$C R F=3$ & 782 (13.9\%) & 110 (3.4\%) & 276 (10.7\%) & $60(4.7 \%)$ & $19(8.5 \%)$ & $10(7.8 \%)$ & $<0.001$ & 0.008 \\
\hline $\mathrm{CRF}=4$ & $168(3.0 \%)$ & $21(0.6 \%)$ & $41(1.6 \%)$ & $7(0.5 \%)$ & $3(1.3 \%)$ & $0(0 \%)$ & 0.001 & 0.622 \\
\hline
\end{tabular}


Table 4 Multivariate logistic regression analysis

\begin{tabular}{|c|c|c|c|c|c|c|c|}
\hline \multirow[t]{2}{*}{ CRFs } & \multirow[t]{2}{*}{ GG } & \multicolumn{3}{|l|}{$\mathrm{GA}$} & \multicolumn{3}{|l|}{$A A$} \\
\hline & & OR & LL & UL & OR & LL & UL \\
\hline \multicolumn{8}{|l|}{ Male } \\
\hline Hypertension & 1 (ref) & 0.77 & 0.69 & 0.85 & 0.56 & 0.41 & 0.75 \\
\hline Diabetes & 1 (ref) & 0.73 & 0.62 & 0.87 & 0.79 & 0.47 & 1.32 \\
\hline Overweight & 1 (ref) & 0.88 & 0.74 & 1.05 & 0.95 & 0.56 & 1.59 \\
\hline Dyslipidemia & 1 (ref) & 1.05 & 0.94 & 1.16 & 1.00 & 0.75 & 1.34 \\
\hline $\mathrm{CRFs}=1$ & 1 (ref) & 0.95 & 0.83 & 1.08 & 0.93 & 0.66 & 1.31 \\
\hline $\mathrm{CRFs}=2$ & 1 (ref) & 0.72 & 0.63 & 0.83 & 0.46 & 0.31 & 0.69 \\
\hline $\mathrm{CRFs}=3$ & 1 (ref) & 0.59 & 0.48 & 0.73 & 0.40 & 0.21 & 0.77 \\
\hline $\mathrm{CRFs}=4$ & 1 (ref) & 0.40 & 0.22 & 0.71 & 0.57 & 0.13 & 2.38 \\
\hline \multicolumn{8}{|l|}{ Female } \\
\hline Hypertension & 1 (ref) & 1.04 & 0.87 & 1.24 & 1.55 & 1.01 & 2.40 \\
\hline Diabetes & 1 (ref) & 1.17 & 0.83 & 1.66 & 1.41 & 0.61 & 3.25 \\
\hline Overweight & 1 (ref) & 1.06 & 0.75 & 1.49 & 1.57 & 0.72 & 3.41 \\
\hline Dyslipidemia & 1 (ref) & 1.12 & 0.97 & 1.28 & 0.97 & 0.67 & 1.41 \\
\hline $\mathrm{CRFs}=1$ & 1 (ref) & 1.06 & 0.92 & 1.23 & 0.95 & 0.62 & 1.45 \\
\hline $\mathrm{CRFs}=2$ & 1 (ref) & 1.02 & 0.82 & 1.27 & 1.88 & 1.12 & 3.16 \\
\hline $\mathrm{CRFs}=3$ & 1 (ref) & 1.71 & 1.13 & 2.59 & 1.54 & 0.52 & 4.60 \\
\hline $\mathrm{CRFs}=4$ & 1 (ref) & 1.04 & 0.27 & 3.97 & Non & Non & Nor \\
\hline
\end{tabular}

ALDH2 activation, which plays key roles in clearing toxic aldehydes, improving mitochondrial function, and remodeling ventricular function, has been shown to be protective against the development of CVDs [14-19, 25], suggesting that $A L D H 2$ gene mutation should be harmful for human health. However, the results of clinical trials have been inconsistent, with many of them indicating a protective effect of the A allele against hypertension, dyslipidemia, and diabetes $[3,4,21,26]$. In this study, we found that the A allele may be more likely to be protective against clustering CRFs, especially hypertension and diabetes in males, though not in females. The contradictory results between basic research and clinical studies, and between males and females, could be explained by the influence of lifestyles, especially the amount and pattern of alcohol consumption. A study based on the China Kadoorie Biobank reported that 33\% of males drank alcohol in most weeks, mainly as spirits, while only $2 \%$ of females did so [13]. Because of issues with alcohol tolerance, including uncomfortable feelings such as flush, dizziness, vomiting, and even exhaustion, individuals carrying the A allele, especially those with the AA genotype, usually drink less (GG: $157 \mathrm{~g} /$ week; AG: $37 \mathrm{~g} /$ week; AA: $3 \mathrm{~g} /$ week) [13]. Furthermore, alcohol intake has been found to be closely associated with an increased risk of CVDs [4-7], and reducing alcohol intake can lower blood pressure in a dose-dependent manner [25]. Therefore, it is very likely that the influence of the different $A L D H 2$ rs671 gene polymorphisms on the prevalence of CRFs is substantially mediated by the amount and pattern of alcohol consumption. Interestingly, we also found that the frequency of AA in individuals $\geq 65$ years old was lower than in other age groups, especially $18-29$, with $p=0.01$, which may imply that the $A L D H 2$ rs671 mutation can induce other mortal diseases and aging independently of CVDs [26, 27].

In this study, we found that, compared with GG carriers, males with GA and AA were less likely to have hypertension. Our results are consistent with a case control study which found that those carrying the A allele were at a lower risk of essential hypertension in males [AA/ AG vs. GG: OR $(95 \% \mathrm{CI})=0.76(0.58-0.98)]$, but not in females [21]. However, our results are contrary to a crosssectional study, which found that the individuals with the rs671 A allele were at higher risk for the development of essential hypertension [28]. In that study, the association was not evaluated separately for males and females, and based on our data, that could have substantially influenced the results. Moreover, our data on the relationship between $A L D H 2$ rs671 genotype and the distributions of TC, TG, and HDL-C, are consistent with previous studies $[4,26,29]$. However, the relationship between rs671 and the prevalence of dyslipidemia as such was not recognized in those studies $[4,26,29]$. Also, we found that the individuals with the rs671 A allele had lower Glu levels and lower prevalence of diabetes, though multivariate 
logistic regression analysis results didn't show that the A allele was significantly protective for diabetes in either males or females. This is similar to a previous Mendelian randomization analysis, which showed that the $\mathrm{A}$ allele in males was significantly associated with decreased diabetes risk for both the overall population $(\mathrm{OR}=0.716$, 95\% CI: $0.567-0.904, p=0.005)$ and moderate drinkers $(\mathrm{OR}=0.564,95 \% \mathrm{CI}: 0.355-0.894, p=0.015)$ [30]. Interestingly, another study found that the individuals with the A allele had a lower incidence of microvascular complications associated with alcohol consumption, but a higher incidence of macrovascular complications irrespective of alcohol consumption [31]. This also implied that the incidence of CRFs could be mediated by both genetics and lifestyle factors such as alcohol assumption.

Although there have been many other studies exploring and evaluating the association between $A L D H 2$ genotype and many diseases including CVDs and their risk factors, most of them were animal experiments. Epidemiological studies did not emerge until recently, and most have focused on the association between $A L D H 2$ and single CRFs, rather than clustering CRFs. In this study, we derived clinical big data from the HIS and LIS of PUMCH, which was simple, cost-efficient and a good reflection of the general population. With all individuals represented in PUMCH being analyzed over a fiveyear period by the same analytical systems, variation due different methods or facilitates was avoided, and the demographic information and clinical laboratory measurements were thorough. Furthermore, we were able to analyze hypertension, diabetes, obesity, and dyslipidemia simultaneously, while correcting for covariations via multivariate logistic regression analysis.

However, some limitations of this study are notable. Alcohol intake was not considered in the evaluation, and other important factors such as smoking and socioeconomic situation were also lacking. Also, in this crosssectional study, the major CRFs, including hypertension, diabetes, obesity, and dyslipidemia, were assessed based only on single test of the corresponding clinical measurements. Casual inferences from this study should therefore be avoided. In the future, long term follow-up cohort studies considering more details, especially the pattern of alcohol consumption, are needed to further explore the causal relationships suggested by our data.

\section{Conclusion}

Our study indicates that the $A L D H 2$ gene polymorphism is associated with clustering CRFs, and that the rs671 A allele may be protective against clustering CRFs in males. This is likely mediated by alcohol intake or related lifestyle factors associated with this genetic variant.

\section{Supplementary information}

Supplementary information accompanies this paper at https://doi. org/10.1186/s12872-020-01787-5.

Additional file 1: Supplemental Table 1. The frequency of ALDH2 rs671 genotype by age and sex.

\section{Abbreviations}

CVDs: Cardiovascular diseases; CRFs: Cardiovascular disease risk factors; ALDH2: Aldehyde dehydrogenase 2; HIS: Hospital Information System; LIS: Laboratory Information System; PUMCH: Peking Union Medical College Hospital; BMI: Body mass index; Alb: Albumin; ALT: Alanine aminotransferase; AST: Aspartate aminotransferase; TBil: Total bilirubin; Cr: Creatinine; Glu: Glucose; TC: Total cholesterol; TG: Triglyceride; HDL-C: High density lipoprotein cholesterol; LDL-C: Low density lipoprotein cholesterol; SBP: Systolic blood pressure; DBP: Diastolic blood pressure; OR: Odds ratio; Cl: Confidence interval.

\section{Acknowledgements}

None.

\section{Authors' contributions}

DCW, YTZ, LQ, SLY, and TDX designed the experiment. LQ, DCW, SLY, and TDX analyzed the data. DCW, YTZ, LQ, SLY, HLL, JW, YCY, and SBL were involved in scientific discussion. DCW, YTZ, LQ, TDX, HLL, SLY, JW, and YCY drafted and revised the manuscript. The author(s) read and approved the final manuscript.

\section{Funding}

This study was supported by grants from the Key Research and Development Program of Ningxia [2018BFG02010], and the CAMS Innovation Fund for Medical Sciences (CIFMS-2018-12M-Al-005). The funding bodies played no role in the design of the study and collection, analysis, and interpretation of data and in writing the manuscript.

\section{Availability of data and materials}

The datasets generated and analysed during the current study are available from the corresponding author on reasonable request. The datasets generated and/or analysed during the current study are available in the National Center for Biotechnology Information repository, https://www.ncbi.nlm.nih. gov/gene/217.

\section{Ethics approval and consent to participate}

Ethical approval was obtained from the Ethics Committee of Peking Union Medical College Hospital of the Chinese Academy of Medical Sciences (protocol number: S-K1114). All the data obtained was anonymized. The need for consent was waived by the Ethics Committee of Peking Union Medical College Hospital of the Chinese Academy of Medical Sciences.

\section{Consent for publication}

Not applicable.

\section{Competing interests}

None.

Received: 1 August 2020 Accepted: 18 November 2020

Published online: 04 December 2020

\section{References}

1. Macek P, Zak M, Terek-Derszniak M, Biskup M, Ciepiela P, Krol H, et al. Age-dependent disparities in the prevalence of single and clustering cardiovascular risk factors: a cross-sectional cohort study in middle-aged and older adults. Clin Interv Aging. 2020;15:161-9.

2. Palazón-Bru A, Ferri-Rufete D, Mares-García E, Durazo-Arvizu R, DivisónGarrote J, Carbayo-Herencia J, et al. Clusters of cardiovascular risk factors and their impact on the 20-year cardiovascular risk in a general population. J Cardiovasc Nurs. 2020;35(2):210-6. 
3. GBD 2017 Causes of Death Collaborators. Global, regional, and national age-sex-specific mortality for 282 causes of death in 195 countries and territories, 1980-2017: a systematic analysis for the Global Burden of Disease Study 2017. Lancet. 2018;392(10159):1736-88.

4. Taylor AE, Lu F, Carslake D, Hu Z, Qian Y, Liu S, et al. Exploring causal associations of alcohol with cardiovascular and metabolic risk factors in a Chinese population using Mendelian randomization analysis. Sci Rep. 2015;5:14005

5. Shin MJ, Cho Y, Davey Smith G. Alcohol consumption, aldehyde dehydrogenase 2 gene polymorphisms, and cardiovascular health in Korea. Yonsei Med J. 2017;58(4):689-96.

6. Cho Y, Shin SY, Won S, Relton CL, Davey Smith G, Shin MJ. Alcohol intake and cardiovascular risk factors: a Mendelian randomisation study. Sci Rep. 2015;5:18422

7. Zhao D, Liu J, Xie W, Qi Y. Cardiovascular risk assessment: a global perspective. Nat Rev Cardiol. 2015;12(5):301-11.

8. World Health Organization, Global status report on alcohol and health 2018. 2018.

9. Manthey J, Shield KD, Rylett M, Hasan OSM, Probst C, Rehm J. Global alcohol exposure between 1990 and 2017 and forecasts until 2030: a modelling study. Lancet. 2019;393(10190):2493-502.

10. Yokoyama A, Omori T, Yokoyama T. Alcohol and aldehyde dehydrogenase polymorphisms and a new strategy for prevention and screening for cancer in the upper aerodigestive tract in East Asians. Keio J Med. 2010;59(4):115-30.

11. Yukawa Y, Muto M, Hori K, Nagayoshi H, Yokoyama A, Chiba T, et al. Combination of $\mathrm{ADH}_{1} \mathrm{~B}^{*} 2 / \mathrm{ALDH}_{2}{ }^{*} 2$ polymorphisms alters acetaldehydederived DNA damage in the blood of Japanese alcoholics. Cancer Sci. 2012;103(9):1651-5.

12. Li H, Borinskaya S, Yoshimura K, Kal'ina N, Marusin A, Stepanov V, et al. Refined geographic distribution of the oriental ALDH2*504Lys (nee 487Lys) variant. Ann Hum Genet. 2009;73(Pt 3):335-45.

13. Millwood IY, Walters RG, Mei XW, Guo Y, Yang L, Bian Z, et al. Conventional and genetic evidence on alcohol and vascular disease aetiology: a prospective study of 500000 men and women in China. Lancet. 2019;393(10183):1831-42.

14. Mali VR, Pan G, Deshpande M, Thandavarayan RA, Xu J, Yang X, et al. Cardiac mitochondrial respiratory dysfunction and tissue damage in chronic hyperglycemia correlate with reduced aldehyde Dehydrogenase-2 activity. PLoS One. 2016;11(10):e0163158.

15. Gomes KM, Campos JC, Bechara LR, Queliconi B, Lima VM, Disatnik MH, et al. Aldehyde dehydrogenase 2 activation in heart failure restores mitochondrial function and improves ventricular function and remodelling. Cardiovasc Res. 2014;103(4):498-508.

16. Yang MY, Wang YB, Han B, Yang B, Qiang YW, Zhang Y, et al. Activation of aldehyde dehydrogenase 2 slows down the progression of atherosclerosis via attenuation of ER stress and apoptosis in smooth muscle cells. Acta Pharmacol Sin. 2018;39(1):48-58.

17. Endo J, Sano M, Katayama T, Hishiki T, Shinmura K, Morizane S, et al. Metabolic remodeling induced by mitochondrial aldehyde stress stimulates tolerance to oxidative stress in the heart. Circ Res. 2009;105(11):1118-27.

18. Gong D, Zhang H, Hu S. Mitochondrial aldehyde dehydrogenase 2 activation and cardioprotection. J Mol Cell Cardiol. 2013;55:58-63.
19. Liu X, Sun A. Aldehyde dehydrogenase-2 roles in ischemic cardiovascular disease. Curr Drug Targets. 2017;18(15):1817-23.

20. Xia CL, Chu P, Liu YX, Qu XL, Gao XF, Wang ZM, et al. ALDH2 rs671 polymorphism and the risk of heart failure with preserved ejection fraction (HFpEF) in patients with cardiovascular diseases. J Hum Hypertens. 2020;34(1):16-23

21. Wu Y, Ni J, Cai X, Lian FZ, Ma HY, Xu LW, et al. Positive association between ALDH2 rs671 polymorphism and essential hypertension: a case-control study and meta-analysis. PLoS One. 2017;12(5):e0177023.

22. Li DD, Xu T, Cheng XQ, Wu W, Ye YC, Guo XZ, et al. Serum gamma-glutamyltransferase levels are associated with cardiovascular risk factors in China: a Nationwide population-based study. Sci Rep. 2018;8(1):16533.

23. Chobanian AV, Bakris GL, Black HR, Cushman WC, Green LA, Izzo JL Jr, et al. The seventh report of the joint National Committee on prevention, detection, evaluation, and treatment of high blood pressure: the JNC 7 report. JAMA. 2003;289(19):2560-72.

24. Ma C, Yu B, Zhang W, Wang W, Zhang L, Zeng Q. Associations between aldehyde dehydrogenase $2(\mathrm{ALDH} 2)$ rs671 genetic polymorphisms, lifestyles and hypertension risk in Chinese Han people. Sci Rep. 2017:7(1):11136 Published 2017 Sep 11.

25. Vasdev S, Gill V, Singal PK. Beneficial effect of low ethanol intake on the cardiovascular system: possible biochemical mechanisms. Vasc Health Risk Manag. 2006;2(3):263-76

26. Han S, Zhao X, Zhang X, Xu Y, Geng J, Wang Y. Acetaldehyde dehydrogenase 2 rs671 polymorphism affects hypertension susceptibility and lipid profiles in a Chinese population. DNA Cell Biol. 2019;38(9):962-8.

27. Wu NN, Ren J. Aldehyde dehydrogenase $2(A L D H 2)$ and aging: is there a sensible link? Adv Exp Med Biol. 2019;1193:237-53.

28. Imatoh T, Yengo L, Rocheleau G, Kamimura S, Maeda S, Miyazaki M, et al. ALDH2 polymorphism rs671, but not ADH1B polymorphism rs1229984, increases risk for hypo-HDL-cholesterolemia in a/a carriers compared to the G/G carriers. Lipids. 2018;53(8):797-807.

29. Yokoyama A, Taniki N, Nakamoto N, Tomita K, Hara S, Mizukami T, et al. Associations among liver disease, serum lipid profile, body mass index, ketonuria, meal skipping, and the alcohol dehydrogenase-1B and aldehyde dehydrogenase-2 genotypes in Japanese men with alcohol dependence. Hepatol Res. 2020;50(5):565-77.

30. Peng M, Zhang J, Zeng T, Hu X, Min J, Tian SS, et al. Alcohol consumption and diabetes risk in a Chinese population: a Mendelian randomization analysis. Addiction. 2019:114(3):436-49.

31. Idewaki Y, Iwase M, Fujii H, Ohkuma T, Ide H, Kaizu S, et al. Association of genetically determined aldehyde dehydrogenase 2 activity with diabetic complications in relation to alcohol consumption in Japanese patients with type 2 diabetes mellitus: the Fukuoka Diabetes Registry. PLoS One. 2015;10(11):e0143288.

\section{Publisher's Note}

Springer Nature remains neutral with regard to jurisdictional claims in published maps and institutional affiliations.

Ready to submit your research? Choose BMC and benefit from

- fast, convenient online submission

- thorough peer review by experienced researchers in your field

- rapid publication on acceptance

- support for research data, including large and complex data types

- gold Open Access which fosters wider collaboration and increased citations

- maximum visibility for your research: over 100M website views per year

At BMC, research is always in progress.

Learn more biomedcentral.com/submissions 